\title{
Hardening Behavior of a 304 Stainless Steel Containing Deformation-Induced Martensite during Static Strain Aging
}

\author{
Sang Hun Lee ${ }^{1, *}$, Jeom Yong Choi ${ }^{2}$ and Won Jong Nam ${ }^{1}$ \\ ${ }^{1}$ School of Advanced Material Engineering, Kookmin University, Seoul 136-702, Korea \\ ${ }^{2}$ Stainless Steel Research Group, POSCO Technical Research Laboratories, POSCO, Pohang P.O. Box 36, 790-785, Korea
}

\begin{abstract}
The hardening behavior of a 304 stainless steel containing deformation-induced martensite during static strain ageing was investigated. Tensile strength increased with the increase of aging temperature. The results of DSC measurements showed that the aging mechanisms would be related to carbon diffusion to dislocations in $\alpha^{\prime}$-martensite and carbon diffusion in austenite. It is found that the increase of strength during strain aging would be attributed to hardening of austenite as well as $\alpha^{\prime}$-martensite. [doi:10.2320/matertrans.MRP2008416]
\end{abstract}

(Received November 7, 2008; Accepted January 19, 2009; Published March 4, 2009)

Keywords: strain aging, austenitic stainless steel, mechanical property, kinetics

\section{Introduction}

Static strain aging (SSA) is well-known phenomenon frequently observed in bcc metals and alloys. This SSA is a consequence of the combined effect of temperatures and plastic strains associated with the deformation process. ${ }^{1)}$ It seems well established that the main mechanism of SSA is closely related to the locking effect on dislocations caused by the formation of atmospheres of interstitial carbon (C) and nitrogen $(\mathrm{N})$ solute atoms dissolved in ferrite. ${ }^{2)}$

Metastable austenitic stainless steels are strengthened by the formation of dislocation structure and/or the deformation-induced martensitic transformation during cold working. ${ }^{3)}$ Furthermore, strain aging at the temperature of $200 \sim 400^{\circ} \mathrm{C}$ would result in the further increase of strength in cold worked metastable austenitic stainless steels. ${ }^{4-6)}$ Proposed mechanisms are (1) the formation of additional martensite after aging ${ }^{5-7)}$ and (2) hardening of $\alpha^{\prime}$-martensite. $^{4,8)}$ Mangonon and Thomas ${ }^{6)}$ have shown that strength increases through the formation of thermal nucleation of $\alpha^{\prime}$-martensite during aging up to $400^{\circ} \mathrm{C}$. According to Mukhopadhyay, et al., ${ }^{7)}$ the further formation of $\alpha^{\prime}$-martensite during strain aging is attributed to a local increase of the Ms temperature caused by a depletion of chromium and carbon in the surrounding matrix due to the precipitation of fine carbides. However, Rathbun, et al. ${ }^{4)}$ reported that strength would increase without the change in the volume fraction of $\alpha^{\prime}$-martensite during strain aging. Since no aging occurs in deformed austenite, the increase of strength must be associated with strengthening of $\alpha^{\prime}$-martensite containing high density of dislocations. Thus, the increase of strength would be closely related to the diffusion of interstitial solute atoms and the interaction of the solutes with dislocations during aging in the temperature range of $100 \sim 400^{\circ} \mathrm{C}$. However, the hardening behavior of cold worked metastable austenitic stainless steels during strain aging can't be fully understood yet with the above mechanisms.

Thus, to investigate the hardening behavior of a cold worked 304 stainless steel during strain aging, the effect

*Graduate Student, Kookmin University of aging temperature on strength and the amount of $\alpha^{\prime}$ martensite was examined in the present work. Additionally, to investigate the dominant mechanism of hardening during strain aging, the changes of mechanical properties, the amount of $\alpha^{\prime}$-martensite, and the kinetic data from DSC (differential scanning calorimetry) were discussed.

\section{Experimental Procedure}

The chemical composition of a 304 austenitic stainless steel used in this study was $0.057 \mathrm{C}, 0.376 \mathrm{Si}, 1.08 \mathrm{Mn}$, $18.14 \mathrm{Cr}, 8.14 \mathrm{Ni}, 0.305 \mathrm{Cu}, 0.146 \mathrm{Mo}$ and $0.033 \mathrm{~N}$ (in mass $\%$ ). An austenite grain size of the hot rolled and annealed sheet was $36.8 \mu \mathrm{m}$. To produce the deformation-induced martensite, samples were cold rolled by $40 \%$ (with $16 \%$ reduction per pass). An aging treatment was performed on cold rolled stainless steel sheets in a heated salt bath in the temperature range of $200 \sim 700^{\circ} \mathrm{C}$ for an hour. Small rectangular specimens were cut from cold rolled and aged samples for X-ray diffraction analysis using $\mathrm{Cu} \mathrm{Ka}$ radiation. To assess the effect of surface constraint on the transformation response, diffraction patterns were obtained on samples chemically thinned to remove specific fractions of the sheet thickness. The solution used for surface removal was a mixture of hydrochloric acid, nitric acid and distilled water in $1: 1: 1$ proportion. The amount of $\alpha^{\prime}$-martensite was also measured using Ferritescope. Ferritescope readings were converted into the amount of $\alpha^{\prime}$-martensite by multiplying with the factor of 1.7 according to Talonen's work. ${ }^{9)}$

$$
\begin{aligned}
& \text { The amount of } \alpha^{\prime} \text {-martensite } \\
& \quad=1.71 \times \text { Ferritescope reading }
\end{aligned}
$$

Tensile tests were performed at room temperature with a constant displacement speed. The initial strain rate was $6.7 \times 10^{-4} \mathrm{~s}^{-1}$. Thermal analysis was performed with a differential scanning calorimeter under a flowing Ar atmosphere. As the DSC peak position depends on the heating rate ${ }^{10)}$ the measured data of the peak positions for different heating rates of $2 \sim 16^{\circ} \mathrm{C} / \mathrm{min}$ were used. To obtain the activation energy, both the Kissinger ${ }^{11)}$ and Chen and Spaepen ${ }^{12)}$ methods were applied in this work. To understand 


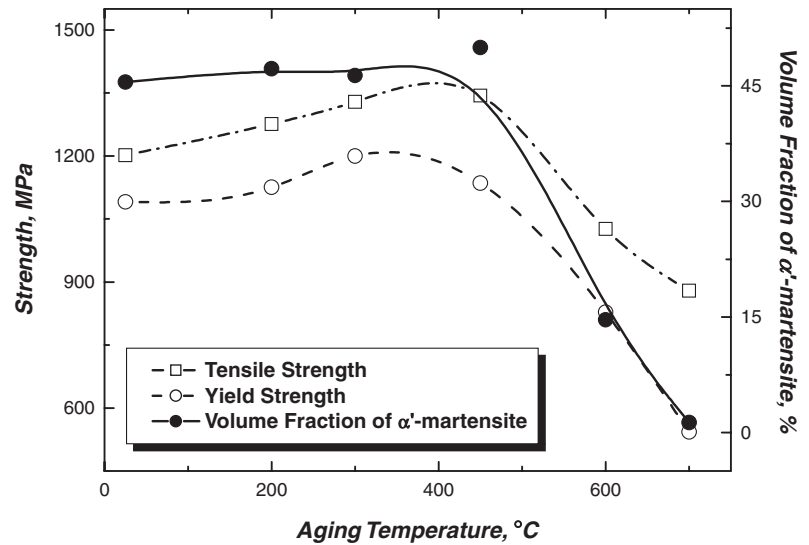

Fig. 1 Effect of aging temperature on mechanical properties and the amount of $\alpha^{\prime}$-martensite in cold rolled 304 stainless steels received $40 \%$ reduction. Samples were aged for an hour.

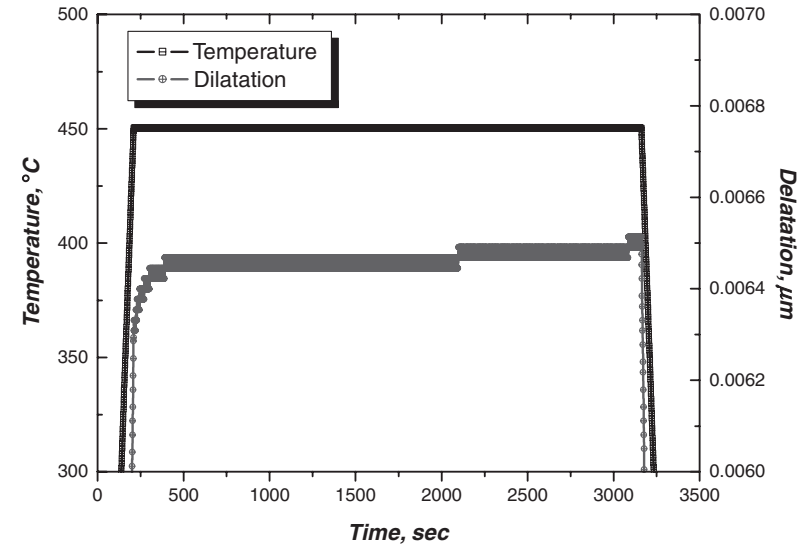

Fig. 2 Dilatation curves, showing the increase of the amount of $\alpha^{\prime}$ martensite with annealing time during heating at $450^{\circ} \mathrm{C}$.
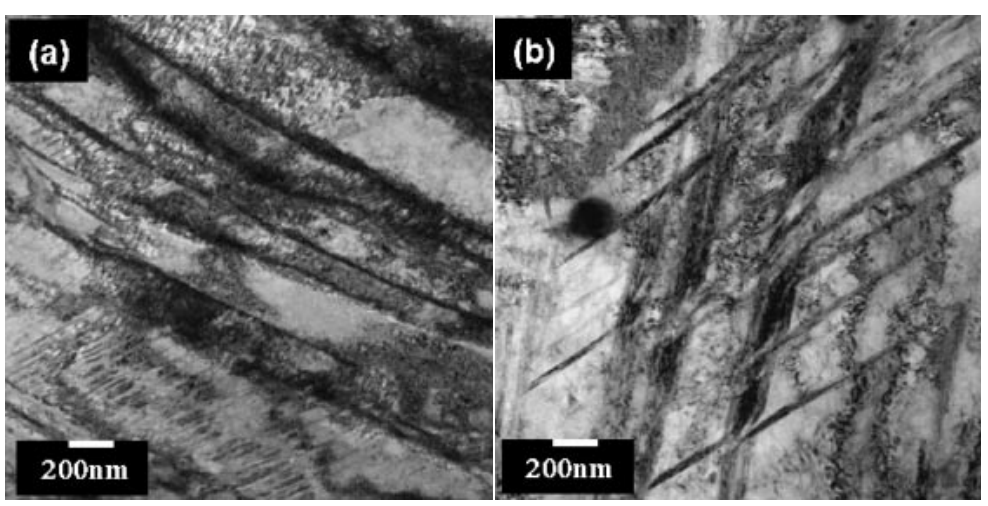

Fig. 3 TEM micrographs of a 304 austenitic stainless steel deformed at room temperature with $40 \%$ reduction.

the kinetics during heating, stainless steel sheets were heated to the desired temperatures at a rate of $4{ }^{\circ} \mathrm{C} / \mathrm{min}$ and then rapidly cooled in water. According to the methods, ${ }^{11,12)}$ the heating rate $(\mathrm{B})$, the apparent activation energy of the process $(\mathrm{Q})$, and the maximum temperature of the peak $\mathrm{T}_{\mathrm{p}}$ are related by the equation

$$
\ln (\alpha)=-\frac{Q}{k_{\mathrm{B}} T_{\mathrm{p}}}+C
$$

where $\mathrm{k}_{\mathrm{B}}$ is the Boltzmann's constant and $\mathrm{C}$ is an integration constant.

\section{Results and Discussion}

\subsection{Mechanical properties}

Figure 1 shows the effect of aging temperature on tensile strength, yield strength and the amount of $\alpha^{\prime}$-martensite in 304 stainless steels cold rolled and aged for $1 \mathrm{~h}$. The variation of yield strength with aging temperature is similar to that of tensile strength, except for the peak temperature of $300^{\circ} \mathrm{C}$. Tensile strength increases continuously up to the aging temperature of $450^{\circ} \mathrm{C}$, and then decreases rapidly due to the reverse transformation of $\alpha^{\prime}$-martensite to austenite. ${ }^{13)}$ The similar shapes of tensile strength and the amount of $\alpha^{\prime}$ martensite in Fig. 1 indicates that the increment of tensile strength during aging must be closely related to the variation in the amount of $\alpha^{\prime}$-martensite. The amount of $\alpha^{\prime}$-martensite calculated from Ferritescope readings increases from $45.5 \%$ for a cold rolled sample to $50 \%$ for a sample aged at $450^{\circ} \mathrm{C}$. Additionally, the occurrence of the dilatation during aging at $450^{\circ} \mathrm{C}$ in Fig. 2 also supports the increase in the amount of $\alpha^{\prime}$-martensite with aging. This increase in the amount of $\alpha^{\prime}$ martensite with aging provides the evidence for the additional formation of $\alpha^{\prime}$-martensite during aging. ${ }^{5-7)}$ However, it is difficult to conclude that only the increased amount of $\alpha^{\prime}$ martensite contributes to the increase of tensile strength in aged samples. Assuming that the increased amount of $\alpha^{\prime}$ martensite, $4.5 \%$, causes the increment of tensile strength, $140 \mathrm{MPa}$, during aging at $450^{\circ} \mathrm{C}$, the calculated contribution of aged austenite to tensile strength would become ignored. Thus, there must be other factors on tensile strength of aged samples.

Figure 3 shows the typical microstructure of the $40 \%$ deformed 304 austenitic stainless steel, revealing microstructures of $\alpha^{\prime}$-martensite with high density of dislocations (Fig. 3(a)) and deformed austenite with micro-twins (Fig. 3(b)). The closer examination of the XRD patterns of a 304 stainless steel deformed $40 \%$ and aged at various temperatures reveals that phase transformation does not occur during strain aging up to $450^{\circ} \mathrm{C}$. To understand the behavior of austenite and $\alpha^{\prime}$-martensite during aging, hardness of each phase was measured using a nano-indenter (Fig. 4). Hardness of $\alpha^{\prime}$-martensite increases from $4.6 \mathrm{GPa}$ (cold rolled) to $5.4 \mathrm{GPa}$ (aged at $450^{\circ} \mathrm{C}$ ) by $17.4 \%$, while that 


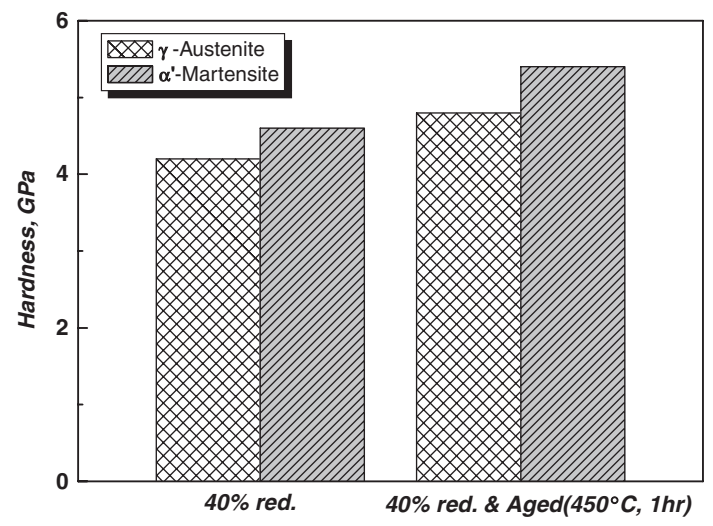

Fig. 4 Effect of static strain aging on hardness of austenite and $\alpha^{\prime}$ martensite in cold rolled 304 stainless steels received $40 \%$ reduction.

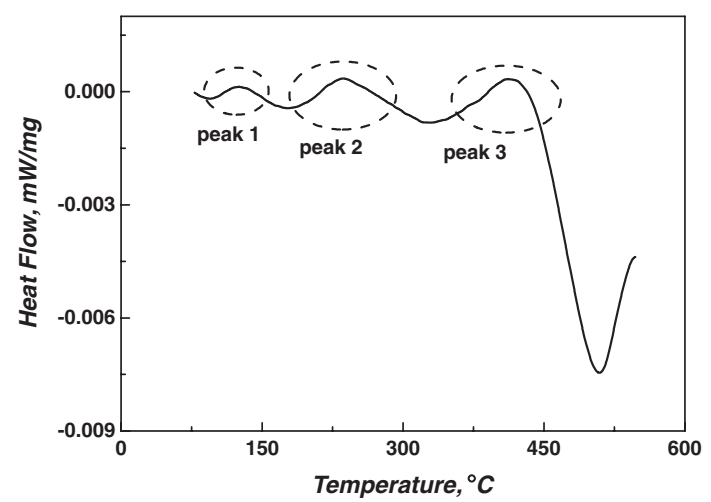

Fig. 5 DSC curves of a $40 \%$ cold rolled sample and a reheated sample, with the heating rate of $4{ }^{\circ} \mathrm{C} / \mathrm{min}$.

of austenite increases from 4.2 to $4.8 \mathrm{GPa}$ by $14.3 \%$. These results indicate that hardness values of both $\alpha^{\prime}$-martensite and austenite obviously increase during static aging. It is also noted that the increase of hardness is more pronounced in $\alpha^{\prime}$ martensite than austenite during aging at $450^{\circ} \mathrm{C}$. This means that the age hardening operates more effectively in $\alpha^{\prime}$ martensite rather than in deformed austenite.

\subsection{Kinetics of strain aging}

The kinetics of strain aging was evaluated on the cold rolled material using a differential scanning calorimeter (DSC). The DSC curves in Fig. 5 reveal three exothermic peaks, which represent the different stages occurred during aging of a 304 stainless steel deformed $40 \%$. The temperature range is found as $100 \sim 150^{\circ} \mathrm{C}$ for the first peak, $180 \sim 270^{\circ} \mathrm{C}$ for the second peak and $350 \sim 450^{\circ} \mathrm{C}$ for the third peak, respectively. Additionally, the presence of an endothermic peak around $500^{\circ} \mathrm{C}$ implies that the reversion of $\alpha^{\prime}$-martensite to austenite begins at above ageing temperature of $450^{\circ} \mathrm{C} .{ }^{14)}$

The values of the parameter $\mathrm{Q}$, can give important information concerning the mechanisms of aging. The apparent activation energy of DSC peaks obtained by analyzing Kissinger plot (Fig. 6) would be useful for understanding the mechanisms of the each stage of static aging more precisely. Figure 6 shows plots of $\ln (\alpha)$ (where $\alpha=$ $\mathrm{B} / \mathrm{T}^{2}{ }_{\mathrm{p}}{ }^{11)}$ and $\alpha=\mathrm{B} / \mathrm{T}_{\mathrm{p}}{ }^{12)}$ ) against $1 / \mathrm{k}_{\mathrm{B}} \mathrm{T}_{\mathrm{p}}$ and the resultant $\mathrm{Q}$ values calculated from each slope. The two methods show a reasonable agreement with each other, yielding $Q$ values

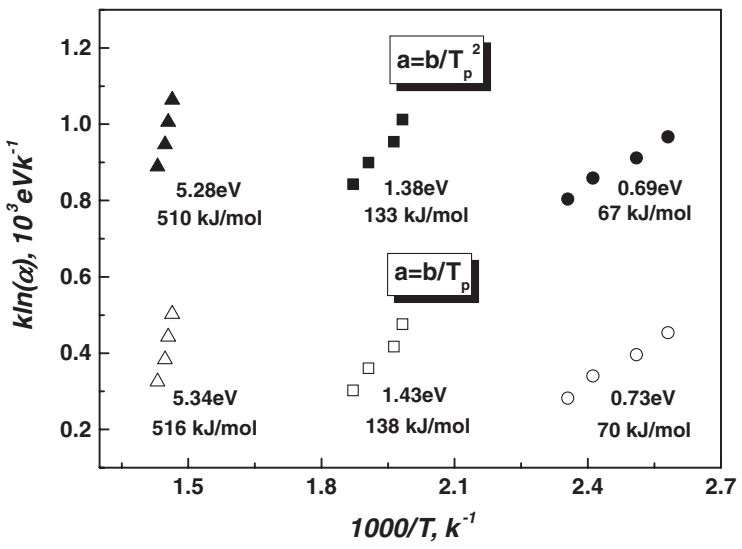

Fig. 6 Calculated apparent activation energy using Kissinger plot of the maximum peak temperatures in the DSC curves.

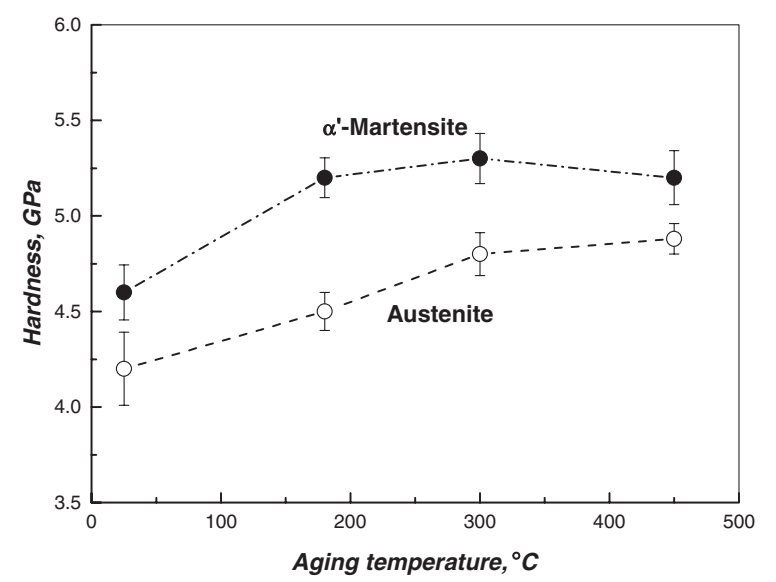

Fig. 7 The hardness of austenite and $\alpha^{\prime}$-martensite in 304 stainless steels cold rolled and heated to 180,300 and $450^{\circ} \mathrm{C}$ with the heating rate of $2{ }^{\circ} \mathrm{C} / \mathrm{min}$.

of $0.69 \sim 0.73 \mathrm{eV} \quad(67 \sim 70 \mathrm{~kJ} / \mathrm{mol})$ for the first peak, $1.38 \sim 1.43 \mathrm{eV}(133 \sim 138 \mathrm{~kJ} / \mathrm{mol})$ for the second peak and $5.28 \sim 5.34 \mathrm{eV}(510 \sim 516 \mathrm{~kJ} / \mathrm{mol})$ for the third peak.

The apparent activation energy of the first peak, 67 70 $\mathrm{kJ} / \mathrm{mol}$, is close to the activation energy for the diffusion of carbon atoms in ferrite, $66.9 \mathrm{~kJ} / \mathrm{mol}^{15)}$ This confirms that the mechanism for the first peak of strain aging $\left(100 \sim 150^{\circ} \mathrm{C}\right)$ is closely related to the redistribution of interstitial solute carbon atoms to dislocations in $\alpha^{\prime}$-martensite containing high density of dislocations. The interaction of carbon atoms with dislocations in $\alpha^{\prime}$-martensite would result in the rapid increase of hardness in $\alpha^{\prime}$-martensite when heated to $180^{\circ} \mathrm{C}$ (Fig. 7). Meanwhile, the apparent activation energy of the second peak, 133 138 kJ/mol, coincides with the activation energy for carbon diffusion in austenite, $134 \sim 136 \mathrm{~kJ} / \mathrm{mol}^{16}{ }^{16}$ According to Fujita, et al., ${ }^{17)}$ the segregation of solute atoms on the stacking fault known as the Suzuki effect can occur in a deformed and annealed 304 stainless steel. Thus, it is expected that the presence of the second peak $\left(180 \sim 270^{\circ} \mathrm{C}\right)$ might be related to the segregation of solute carbon atoms to dislocations and micro-twins in deformed austenite during aging. Accordingly, in Fig. 7, hardness of austenite increase steadily up to $300^{\circ} \mathrm{C}$ and hardness of $\alpha^{\prime}$-martensite increases slightly due to the occurrence of carbide precipitation and the progress of recovery in $\alpha^{\prime}$-martensite. 
The measured activation energy of the third peak, $510 \sim 516 \mathrm{~kJ} / \mathrm{mol}$, seems considerably higher than the reported Q values available for steels, such as $\mathrm{Q}_{\gamma}{ }^{\mathrm{Cr}}=405 \mathrm{~kJ} /$ $\mathrm{mol}, \mathrm{Q}_{\alpha}{ }^{\mathrm{Cr}}=343 \mathrm{~kJ} / \mathrm{mol}, \mathrm{Q}_{\gamma}{ }^{\mathrm{Ni}}=280 \mathrm{~kJ} / \mathrm{mol}$ and $\mathrm{Q}_{\alpha}{ }^{\mathrm{Ni}}=$ $358 \mathrm{~kJ} / \mathrm{mol}^{18)}{ }^{18}$ There has been no clear explanation regarding the mechanism of the third peak. The occurrence of the third peak in the temperature range of $350 \sim 450^{\circ} \mathrm{C}$ might be related to one or more of microstructural evolution occurred at high temperatures, such as recovery of $\alpha^{\prime}$-martensite, or the additional formation of $\alpha^{\prime}$-martensite during aging. The activation energy of the third peak, $510 \sim 516 \mathrm{~kJ} / \mathrm{mol}$, has the order of magnitude of the sum of the apparent activation energy for carbon diffusion in austenite and for $\mathrm{Cr}$ diffusion in austenite, $538 \sim 543 \mathrm{~kJ} / \mathrm{mol}$. Additionally the volume fraction of $\alpha^{\prime}$-martensite in Fig. 1 increases rapidly during aging at the temperature of $450^{\circ} \mathrm{C}$ which corresponds to the third peak in Fig. 5. Thus, although the authors do not have physical insight at the moment, the diffusion of carbon and $\mathrm{Cr}$ atoms in austenite, which is related to the depletion of carbon and $\mathrm{Cr}$ in the surrounding matrix caused by the precipitation of fine carbides, ${ }^{7)}$ seems most probable for the presence of the third peak.

\section{Conclusions}

In conclusion, the increased amount of $\alpha^{\prime}$-martensite during aging provides the evidence for the additional formation of $\alpha^{\prime}$-martensite in a deformed 304 stainless steel. Hardness values of both $\alpha^{\prime}$-martensite and austenite obviously increase during static aging. Thus, the increase of tensile strength during strain aging would be attributed to hardening of austenite as well as $\alpha^{\prime}$-martensite and the additional formation of $\alpha^{\prime}$-martensite.

\section{Acknowledgements}

The authors would like to acknowledge the support of POSCO.

\section{REFERENCES}

1) J. R. Hämmerle, L. H. de Almeida and S. N. Monteiro: Scr. Mater. 50 (2004) 1289

2) R. E. Reed-Hill: Physical Metallurgy Principles, (JPWS Publ. Co, 3rd ed., Boston, 1994).

3) V. F. Zackay, E. R. Parker, D. Fahr and R. Busch: Trans. ASM 60 (1967) 252.

4) R. W. Rathbun, D. K. Matlock and J. G. Speer: Scr. Mater. 42 (2000) 887.

5) A. N. Chukhleb and V. P. Martynov: Phys. Met. Metall. 10 (1960) 80

6) P. L. Mangonon and G. Thomas Jr.: Metall. Trans. 1 (1970) 1587.

7) C. K. Mukhopadhyay, T. Jayakumar, K. V. Kasiviswanathan and B. Raj: J. Mater. Sci. 30 (1995) 4556.

8) S. Okamoto, D. K. Matlock and G. Krauss: Scr. Metall. 25 (1991) 29.

9) J. Talonen, P. Aspegren and H. Hänninen: Mat. Sci. Tech. 20 (2004) 1506.

10) R. C. Picu and D. Zhang: Acta Mater. 52 (2004) 161.

11) H. E. Kissinger: Anal. Chem. 29 (1957) 1702.

12) L. C. Chen and F. Spaepen: J. Appl. Phys. 69 (1991) 679.

13) B. R. Kumar, B. Mahato, N. R. Bandyo-padhyay and D. K Bhattacharya: Metall. Mater. Trans. A 36A (2005) 3165.

14) B. R. Kumar, A. K. Singh, B. Mahato, P. K. De, N. R. Bandyopadhyay and D. K. Bhattacharya: Mater. Sci. Eng. A 429 (2006) 205.

15) C. S. Roberts, B. L. Averbach and M. Cohen: Trans. ASM 45 (1953) 576.

16) R. W. K. Honeycombe: The Plastic Deformation of Metals, 2nd ed, (Arnold, London, 1984) p. 145.

17) M. Fijita, Y. Kaneko, A. Nohara, H. Saka, R. Zauter and H. Mughrabi: ISIJ Int. 34 (1994) 697.

18) R. W. K. Honeycombe and H. K. D. H. Bhadeshia: Steels-microstructure and properties, 2nd ed, (Arnold, London, 1995) p. 7. 